\title{
EL CONCEPTO DE COMPLEXIÓN Y ALMA EN TOMÁS DE AQUINO Y GALENO
}

\author{
Carmen Martínez Sendra \\ Profesora de Filosofía. Logroño
}

El tema propuesto en este congreso sugiere la posibilidad de abordar los límites de la razón en el pensamiento medieval desde el punto de vista biológico. ¿Cuál es la relación que se establece en el medioevo entre el aspecto somático y el racional? ¿Es la razón realmente autónoma? ¿No hay en el hombre algunas inclinaciones naturales que le disponen para obrar de un modo determinado?. Pienso que es posible responder parcialmente a estas preguntas si se ponen en conexión los conocimientos fisiológicos de la época con los psicológicos. En efecto, la psicología y la medicina de la Edad Media no son saberes independientes que discurren por cauces separados. Al contrario, son saberes que arrancan de un mismo punto y se inspiran en idéntica fuente: la cultura griega cuyas grandes figuras médicas son Hipócrates y Galeno. Se puede afirmar sin titubeos que la medicina escolástica es esencialmente galénica. Sus tesis se conservan, se depuran y se ordenan en el transcurso de la Edad Media. ${ }^{1}$

Galeno (c. 130 - c. 200 d. de C.) conoció las obras platónicas y aristotélicas. En Esmirna siguió los cursos del neoplatónico Albino y del neopitagórico Nicómaco. Más adelante residió en Corinto, Alejandría y Egipto. Se transladó a Roma hacia el año 163 donde frecuentó las clases de Eudemo, aristotélico de gran prestigio. Se inclinó finalmente por las tesis del Estagirita, llegando a afirmar que su máxima aspiración era completar y continuar la obra aristotélica. $^{2}$

Parece fácil comprobar históricamente que las tesis galénicas impregnadas de términos aristotélicos, eran aceptadas por la mayor parte de los médicos del siglo XIII.

1 Federici Vesconi, G., Médecine, science et philosophie chez Jacques de Forli, en VV. AA., L' homme et son univers au Moyen âge. Actes du septième congrès international de philosophie médiévale. Editions de L'Institut Superieur de philosophie, 1986, II, pp 699-708.

2 Sobre la biografía de Galeno y la influencias de Aristóteles en sus escritos biológicos, confróntese García Ballester, L., Galeno. Guadarrama, Madrid. 1972, pp 26-148; y Laín Entralgo, P., Historia Universal de la Medicina. Ed. Salvat, Barcelona, 1972, II, pp70-90. 
La doctrina tomista tiene como sustrato fisiológico las tesis galénicas. ${ }^{3}$ Por este motivo es útil comparar uno de los conceptos más utilizados en medicina y psicología: el concepto de «complexión»

\section{EL CONCEPTO DE «COMPLEXIÓN» EN GALENO Y TOMÁS DE AQUINO}

Este concepto de «complexión» ha sido bastante confuso a lo largo de la historia. Sus orígenes se remontan a las doctrinas hipocráticas. Brevemente cabe señalar que Galeno utiliza la noción de complexión («krasis») para referirse a la constitución individual. Este término fue vertido al latín con el vocablo «temperamentum» 0 «complexio». ${ }^{4}$ Apoyándose en los escritos hipocráticos y en las aportaciones biológicas aristotélicas sistematizó los elementos que integran la composición de los cuerpos humanos utilizando para ello diferentes conceptos estequiológicos, entre los que destacan especialmente los de elemento y humor. ${ }^{5}$

Siguiendo la doctrina hipocrática afirma que la diversidad de naturalezas orgánicas depende de los diferentes temperamentos. Estos temperamentos son hereditarios, aunque pueden variar por la influencia de los hábitos alimenticios, de la zona geográfica, del clima, etc.

El Aquinate conserva la noción clásica de complexión considerando que es privativo del hombre poseer la mejor complexión de todos los animales, puesto que su complexión somática debe favorecer la característica fundamental del hombre: su racionalidad. Es necesario que el cuerpo, que debe unirse sustancialmente al alma sea realmente apto para facilitar el proceso del conocimiento. ${ }^{6}$

La complexión humana resulta tan equilibrada que no domina en el hombre pasión alguna, a no ser por enfermedad, o por defectos congénitos en el temperamento, o por hábitos viciosos. Por el contrario, las diferentes especies animales reciben una complexión en la que sobresale alguna cualidad que favorezca su instinto de supervivencia.?

Junto a lo anteriormente dicho hay que tener en cuenta que una mala complexión puede ocasionar trastornos en la naturaleza humana, inclinando al hombre a realizar acciones en contra de su propia naturaleza y a deleitarse en objetos que le perjudican.

La trascendencia del concepto de complexión es más clara cuando se relaciona con la a airmación mantenida por la tradición galénica de que las costumbres del alma son consecuencia del cuerpo o dicho de otro modo, que la complexión corporal dispone a los sujetos hacia

3 Paniagua, J.A., La patología general en la obra de Arnau de Vilanova, en «Archivo Iberoamericano», I (1940), p. 53.

4 Cfr. Pinillos, J.L.; López Piñero, J.M., y García B., L., Constitución y personalidad. C.S.I.C. Ed. Guerri. Madrid, 1966, pp. 35-37.

5 García Ballester, L., Galeno. Ed. Guadarrama, Madrid. 1972, pp. 115-167.

6 I, q. 76, a. 5.

7. I-II, q. 46 , a. 5 . 
un determinado estado anímico. Tanto Galeno como Santo Tomás descubren la relación que puede darse entre la complexión, la vida psíquica y la conducta humana.

Ya en la época de Galeno se pensaba que todo cuerpo estaba constituido por cuatro elementos de cuño presocrático: agua, tierra, aire y fuego. Estos elementos implican a su vez dos pares de enantiosis (cualidades contrarias). Así pues, el fuego se relaciona con lo caliente y seco, el aire con lo caliente y húmedo, la tierra con lo frío y seco, el agua con lo frío y húmedo. Dichas cualidades de elementos se manifiestan en la composición humoral del cuerpo de humano. Existen cuatro humores básicos que son : la bilis amarilla, tambien llamada cólera, la sangre, la bilis negra o cólera negra y la flema o pituita. Pues bién, cada uno de los temperamentos que considera Santo Tomás se relaciona con los elementos, enantiosis y humores citados. Para entender mejor esta teoría se presenta el siguiente diagrama:

\begin{tabular}{llll} 
Elemento & Humor & Enantiosis & Temperamento \\
\hline Fuego & Bilis amarilla & Caliente-seca & Colérico \\
Aire & Sangre & Caliente-húmedo & Sanguíneo \\
Tierra & Bilis negra & Fría-seca & Melancólico \\
Agua & Flema & Fría-húmeda & Flemáticos
\end{tabular}

\section{CARACTERÍSTICAS DE LOS TEMPERAMENTOS}

Así pues Santo Tomás presenta una cuádruple clasificación:

A) Coléricos: los hombres de complexión colérica se caracterizan porque abunda en ellos la bilis amarilla , cuya propiedad es moverse con gran rapidez y viveza en el interior del organismo. Por este motivo, el temperamento de los coléricos es con frecuencia brusco, airado, pródigo en reacciones impetuosas y violentas. Propensos a la ira. Con frecuencia debido a la celeridad que caracteriza el movimiento de este humor son los coléricos, hombres precipitados en sus juicios, arrastrados fácilmente por la pasión que sienten sin tener en cuenta el dictamen de la razón; son audaces y emprendedores para enfrentarse con las dificultades. ${ }^{8}$

Santo Tomás piensa que para constrir un temperamento equilibrado es necesario que la mezcla de los cuatro humores sea proporcionada.Por esto propone que los coléricos pueden recuperar el equilibrio de su complexión contrarestándola con el elemento opuesto al de su propia complexión. También señala que este temperamento iracundo, tan ligado a la complexión humoral es transmitido de padres a hijos. ${ }^{9}$

Por último establece una gradación en el modo de manifestarse la ira: el inicio de esta pasión recibe el nombre de ira; la manía, segundo momento del proceso, designa una ira

8 I-II, q. 46, a. 5.; I-II, q. 56, a. 4. y I-II, q. 44, a. 1.

9 I-II, q. 46, a. 5. 
permanente, indicando la estabilidad de la pasión; y en tercer lugar señala el furor, que implica un deseo de venganza. ${ }^{10}$

B) Sanguíneo: en las personas sanguíneas abunda la sangre con sus respectivas cualidades que son lo caliente y lo húmedo. Las personas sanguíneas son de complexión débil, de constitución frágil y delicada puesto que el aire es el elemento que abunda en ellas. Dadas estas características no puede predominar en ellas la ira como pasión, sino el amor. ${ }^{11}$

C) Melancólicos: El humor que predomina en ellos es la bilis negra o la cólera negra. El elemento que les corresponde es la tierra con sus enantiosis fría y secca. Coinciden en algunos aspectos con los coléricos por tratarse de un humor similar. Al igual que ellos se enardecen fácilmente puesto que el movimiento de los humores es de gran intensidad y una vez iniciado es difícil de controlar. Es semejante a un incendio -siguiendo el ejemplo de Santo Tomáspropagado en la tierra con gran rapidez.

Como acontece en los coléricos actúan sin tener en cuenta el juicio de la razón, con decisiones precipitadas y con comportamientos faltos de moderación. Experimentan a menudo sentimientos de tristeza y tratan de superar este estado anímico entregándose sin esfuerzo a sus pasiones. ${ }^{12}$ No es extraño verlos refugiados en un mundo fantasioso y ficticio que construyen con su imaginación.

D) Flemáticos: Abunda en ellos la flema o pituita y la enantiosis frío-húmedo. Son individuos de complexión débil, los compara Santo Tomás a la constitución frágil de las mujeres. ${ }^{13}$ Anímicamente son flojos, inconstantes en sus decisiones, remisos en sus acciones, torpes en sus movimientos, no son tenaces y perseverantes en los esfuerzos emprendidos, no se sobreponen con rapidez a las dificultades ni resisten a las impresiones fuerte. Carecen de fuerza de voluntad suficiente para adherirse a aquello que la razón les presenta como bueno.

\section{EL ALMA SEGÚN GALENO}

Una vez analizada la relación existente entre complexión humoral y rasgos psíquicos de los individuos, es necesario encuadrar esta influencia de los elementos fisiológicos dentro de una antropología.

Así pues, la pregunta inmediata es ¿Comparten Galeno y Santo Tomás la noción de alma? ¿Cómo relacionan algo tan íntimo -la complexión individual-con el alma? Santo Tomás deja

\footnotetext{
10 I-II, q. 46, a. 8.

11 I-II, q. 46, a. 2.

12 I-II, q. 46, a. 2.

13 «Impetus autem passionis provenire potest vel ex velocitate, sicut in cholericis vel ex vehementia, sicut in melancholicis, qui propter terrestrem complexionen vehementissime inflammantur. Sicut e contrario contingit quod aliquis non persistat in eo quod consiliatum est, ex eo quod debiliter inhaeret, propter mollitiem complexionis: ut de mulieribus dictum est. Quod etiam videtur in phlegmaticis contingere, propter eamdem causam sicut etiam in mulieribus» (II-II, q. 156, a. 1.).
} 
bien claro en su obra que la noción de alma utilizada por Galeno es insuficiente para explicar la naturaleza del hombre.

No se trata de exponer aquí íntegramente el concepto de alma de la psicología tomista, sino de analizar los motivos por los que no puede compartir la noción de alma utilizada por Galeno.

Galeno hereda de la filosofía griega el concepto de alma como principio de vida y acepta también el esquema tripartito del alma tal como lo expone Platón. A lo largo de su vida va perfilando la noción de alma; como resultado final, identifica la sustancia del alma con la naturaleza del hombre, es decir, con su complexión corporal. ¿Qué motivos tiene Galeno para semejante identificación? Sencillamente la pretension de admitir presupuestos exclusivamente científicos ajenos a teorías metafísicas etéreas que extrapolen realidades no corporales. En - virtud de esta reducción de postulados el alma queda limitada a las dimensiones materiales, sin poder escapar del ámbito cuantitativo. ${ }^{14}$

Galeno identifica la sustancia del alma con la naturaleza del hombre, entendida como pura «krasis» o complexión humoral. La psicología galénica afirma que al alma le corresponden distintas «dynamis» o facultades que manifiestan operativamente su esencia. Las cuatro «dynamis» fundamentales son: «dynamis physikhé» (en virtud de la cual el organismo humano cumple sus funciones vegetativas), «dynamis zotikhé» (gracias a la cual el interior del cuerpo posee un calor propio que se transmite a las partes periféricas y es mantenido por una función respiratoria), «dynamis psykhiké» (rige las operaciones de sensibilidad y movimiento autónomo) y por último, existe una «dynamis» diferente que es la intelectiva y hegemónica. Cada una de las facultades principales se realiza en el ser viviente mediante una serie de potencias secundarias.

Las facultades están en relación directa con la complexión y el lugar corporal donde se localizan. Dicho de otra manera: la actividad del alma es material y tiene lugar en un órgano concreto. No sería lógico que el alma siendo material tuviera compuestos espirituales. Evidentemente sólo puede componerse de las cuatro cualidades fundamentales: humedad, sequedad, frío y calor. La posibilidad de combinar estas cuatro cualidades es infinita. Por este motivo los hombres no tienen todos el mismo tipo de alma. De ahí que su conducta sea diferente.

\section{REFUTACIÓN DE LAS TESIS GALÉNICAS SEGÚN TOMÁS DE AQUINO}

Santo Tomás conoció la opinión de Galeno acerca de la naturaleza del alma y utiliza tres argumentos para refutar esta teoría.

El primer argumento expone que las funciones vegetativas que tienen lugar en el hombre no pueden ejercerse si no existe en el cuerpo un principio de vida que comunique el

14 Laín Entralgo, P., Historia de la medicina. Salvat, 1978, pp. 88-92; Cfr. García B., L., Galeno. Guadarrama, Madrid. 1972, p. 134. 
movimiento. Si el alma se identificara con la complexión serían imposible las operaciones cognoscitivas, no habría articulación entre el conocimiento sensible y el intelectual. Esta visión materialista de Galeno impide las operaciones más nobles del hombre: conocer y querer. La operación de entender no puede ser resultado de un cuerpo. Es un acto del alma.

El segundo argumento explica que la complexión -tanto para Galeno como para Santo Tomás- se reduce a un equilibrio armónico entre cuatro cualidades opuestas y admite variaciones entre las distintas cualidades, excesos y defectos en su composición. Sin embargo, el alma, según las tesis tomistas, como forma sustancial del cuerpo no admite contrarios ni puede sufrir disminuciones ni aumentos.

El tercer argumento que utiliza procede de su convicción acerca del lugar natural al que tienden los cuerpos. Afirma que el movimiento del cuerpo se debe al alma. Este movimiento es de tal naturaleza que permite moverse al hombre en todas las direcciones. Sin embargo, este tipo de movimiento no tendría sentido si el alma siguiera el lugar natural del movimiento dominante de su complexión. ${ }^{15}$

¿Qué le llevó a Galeno a confundir el alma con el temperamento? Para Tomás de Aquino el error radica en que no tuvo en cuenta que la complexión implica una serie de disposiciones en el hombre que influyen en determinadas pasiones; pero no se puede olvidar que las pasiones humanas son causa dispositiva, nunca determinativa de la conducta. No niega que el temperamento disponga a los hombres a actuar de una manera determinada; sin embargo afirma claramente que el ser humano puede controlar sus pasiones y reprimir sus tendencias instintivas. Este hecho no sería posible si no existiera una instancia superior a la complexión corporal. Ahora bien, ¿Qué instancia es de tal característica que pueda dominar el cuerpo? La respuesta tomista es bien conocida «Anima regit corpus et repugnat passionibus, quae complexionem sequuntur». ${ }^{16}$

Una vez establecido este principio, cabe preguntarse ¿Qué relación existe entre la complexión, las pasiones y el alma? ¿Hasta qué punto intervienen el cuerpo y el alma en las pasiones del alma? Santo Tomás aclara con precisión esta relación y señala en este punto el error de las tesis galénicas. El siguiente texto manifiesta claramente su opinión:

«Deceptus autem fuisse videtur ex hoc quod non consideravit aliter passiones attribui complexioni, et aliter animae. Complexioni namque attribuuntur sicut disponenti, et quantum ad id quod est materiale in passionibus, sicut fervor sanguinis et huiusmodi: animae autem tamquam principali causae, ex parte eius quod est in passionibus formale, sicut in ira appetitus vindictae». ${ }^{17}$

Galeno se equivocó por no haber considerado que en las pasiones interviene tanto el cuerpo como el alma. Toda modificación que se observe en las pasiones hay que atribuirla al

15 Estos tres argumentos se encuentran en C.G., L.II, C. LXIII.

16 Ibid.

17 C.G., L.II, C. LXIII. 
cuerpo. Toda reacción fisiológica (hervor de la sangre, secreción de glándulas, alteración de la respiración, etc.) manifiesta la intervención del organismo. La complexión actúa como causa material o dispositiva de la pasión.

De la misma manera que es imprescindible admitir la intervención del cuerpo en las pasiones del apetito sensitivo, es necesario aceptar la intervención del alma en el movimiento pasional. Es preciso aclarar que no se trata de que el alma sea sujeto de pasiones sin más, sino que es sujeto de pasiones «per accidens». ${ }^{18}$

No es objeto de esta comunicación presentar un estudio de las pasiones según la antropología tomista. Por este motivo no se profundiza más en el dinamismo de las pasiones. Sin embargo quedaría incompleta esta exposición si no se aludiera brevemente a la doctrina tomista acerca de la naturaleza del alma y su relación con el cuerpo.

El alma es una sustancia inmaterial, espiritual, que subsiste con independencia del cuerpo. Físicamente simple, no tiene partes yuxtapuestas ni es extensa, no tiene cantidad ni ocupa un lugar en el espacio. Es sin embargo, metafísicamente compuesta. Tiene esencia (forma espiritual) y existencia (acto de ser). Tiene composición de acto y potencia, pero no de materia y de forma. ${ }^{19}$

No puede corromperse: ni «per se» (ẹn sí misma) ni «per accidens» (en función de otro corruptible del cual dependa). Es imposible la corrupción del alma por sí misma, puesto que es simple y tampoco puede corromperse accidentalmente, porque no depende del cuerpo para existir. ${ }^{20}$

Ocupa un lugar central en la metafísica tomista la unión sustancial entre alma y cuerpo. El hombre no aparece constituido como la unión de dos sustancias incomunicables, incapaces de tener una actividad común. El sujeto humano no se puede reducir sólo a una complexión corporal (como pretende Galeno) ni a una espiritualidad pura. El hombre es un compuesto de alma y cuerpo en el que el alma es la forma del cuerpo.

Santo tomás establece dos condiciones para que dos elementos distintos puedan estar unidos sustancialmente. Estas condiciones son:

a) Que la forma (el alma) sea principio de la existencia sustancial de la materia (el cuerpo).

b) Que de la unión de la forma y la materia resulte un sólo ser.

Estas dos condiciones se cumplen en el caso del alma humana. En efecto, siendo una substancia de naturaleza diferente al cuerpo, es también principio formal de su existencia. Reúne también el segundo requisito necesario para una unión sustancial: alma y cuerpo unidos no constituyen dos seres, sino uno sólo. El compuesto que resulta es único.

El cuerpo humano -superior al animal- recibe una sustancia más noble que él, y su unión es tan estrecha que Santo Tomás la declara superior a la que existe entre la materia del fuego y su forma. Se puede decir con propiedad que el alma da vida al cuerpo, es el principio de todas las actividades que experimentamos en nuestro organismo: nutrición, movimiento, conoci-

18 Id., C. LXV

19 I, q.50,a.2.

20 Cfr. C. G., L. II, C. LV. 
miento sensible e intelectual. Este hecho no impide que el alma pueda realizar por sí sola la actividad intelectual.

Comenta Santo Tomás que la unión entre cuerpo y alma es natural. Si bien es verdad que el alma es por naturaleza subsistente y, por lo tanto no necesita del cuerpo para existir, también es cierto que el alma separada del cuerpo no tiene una naturaleza completa y carece de la perfección que le corresponde en tanto que está unida al cuerpo. ${ }^{21}$

Por último, es necesario considerar que el alma es la forma del cuerpo, pero el cuerpo es la razón de su individualidad. Todas las almas son idénticas en cuanto a la naturaleza, pero son diferentes en razón de los cuerpos que informan. El cuerpo de cada hombre justifica la individualidad. El alma es la que hace que el hombre sea hombre y no tenga una esencia diferente a la humanidad; ahora bien, el cuerpo es la razón primordial de que un hombre sea «este hombre» determinado.

De todo lo dicho anteriormente se deduce que el alma no puede identificarse con la complexión como pretende Galeno, ya que no ocupa ningún lugar material, no reside en ningún órgano del cuerpo. Se puede decir que vivifica todas las partes de nuestro organismo, y que como principio vital y forma del cuerpo es inextensa.

21 I, q. 90, a, 4.; III, q.77, a.1. 